\title{
Protocol: Influence of Budesonide and Budesonide/ Formoterol on Asthma Control in Smoking Asthmatic Adults
}

\author{
Louis-Philippe Boulet ${ }^{*}, 1$, Francine Deschesnes ${ }^{1}$, Simone Chaboillez ${ }^{2}$ and \\ Catherine Lemière ${ }^{2}$ \\ ${ }^{I}$ Centre de recherche de institut universitaire de cardiologie et de pneumologie de Québec, Québec, Canada \\ ${ }^{2}$ Hôpital du Sacré-Cour de Montréal, Université de Montréal, Canada
}

\begin{abstract}
Rationale: A reduced response to inhaled corticosteroids (ICS) has been reported in smoking asthmatic patients but the effects of other medications remain to be evaluated in this population.

Subjects and Methods: We evaluated the effects of a combined therapy of budesonide $200 \mu \mathrm{g}$ twice daily and formoterol 6 $\mu \mathrm{g}$ twice daily compared with budesonide $200 \mu \mathrm{g}$ twice daily alone on asthma control questionnaire (ACQ), asthma quality of life questionnaire (AQLQ- Juniper), pulmonary function and airway inflammation, in a cross-over randomized double-blind study with treatment periods of two months separated by a one-month wash-out period. Seventeen smoking and 22 non-smoking patients not using inhaled corticosteroids with slightly uncontrolled mild asthma completed the study.

Results: ACQ and AQLQ scores were similar in both groups at baseline and improved similarly after treatments. $\beta 2-$ agonist use was higher in smokers, regardless of the treatment received $(p=0.03)$, as it was on baseline $(p=0.003)$. Smokers treated with budesonide/formoterol showed an increase in the number of asthma episodes (intercurrent asthma symptoms, $\mathrm{p}=0.016)$ while non-smoking subjects had a significant decrease in these episodes $(\mathrm{p}=0.009)$. No difference was found between smokers and non-smokers in regard to post-treatment airway inflammatory parameters.

Conclusions: No significant differences were found between smoking and non-smoking subjects with mild asthma in regard to clinical changes in asthma control, pulmonary function and airway inflammation following a 2-month treatment period with budesonide or the association of budesonide and formoterol for a period of 2 months. This should be further explored in larger groups of subjects.
\end{abstract}

Keywords: Asthma, formoterol, budesonide, smoking.

\section{INTRODUCTION}

Smoking is associated with a significant morbidity and mortality but unfortunately this habit is still common worldwide [1, 2]. In Canada, about one out of four asthmatic subjects currently smokes, a prevalence similar to the general population $[3,4]$ despite observations of an increased asthmarelated morbidity and decline in pulmonary function in smokers [5-7]. Frequency of respiratory symptoms has been reported to be higher in smoking asthmatic patients and asthma to be more difficult to control than in non-smokers [8-10]. There are increasingly available data on the influence of smoking on pulmonary function of asthmatic subjects and their response to various medications but the optimal treatment of asthma in smokers is still to be determined [9].

Cigarette smoking has been associated with a reduction in the efficacy of inhaled corticosteroid (ICS) treatment in mild asthma, possibly in relation with a change in the type of underlying airway inflammation, with an associated increase

*Address correspondence to this author at the Institut Universitaire de Cardiologie et de Pneumologie de Québec, 2725, Chemin Sainte-Foy, Québec, Qc, GIV 4G5, Canada; Tel: 418-656-4747; Fax: 418-656-4762;

E-mail: lpboulet@med.ulaval.ca in the number of neutrophils [11-13]. The comparative influence of $\beta 2$-agonists or other asthma medications remain however to be documented in this population.

Current guidelines suggest that in mild to moderate steroid-naive subjects ICS are the first choice as initial maintenance therapy although if asthma remains uncontrolled with a low dose of this type of medication, the addition of an inhaled long-acting $\beta 2$-agonist (LABA), ideally in the same inhaler, is considered as a preferred option $[14,15]$. However, we need to determine if this therapeutic strategy is appropriate in smoking asthmatic subjects, in assessing their response to ICS or combination therapy compared to non-smokers.

In this study, we therefore evaluated the effects of a combination of budesonide and formoterol compared to budesonide alone on asthma control, asthma-related quality of life, pulmonary function and airway inflammation in mild smoking asthmatic subjects not using inhaled corticosteroids or any other anti-inflammatory medication. 


\section{METHODS}

\section{Study Design}

This was a cross-over double-blind randomized study with treatment periods of two months separated by a washout period of one month. After a 2 -week run-in period on short-acting inhaled bronchodilator on demand, both groups of subjects (smokers and non-smokers) were randomized to receive either budesonide $\left(\right.$ Pulmicort ${ }^{\mathrm{R}}$ ), $200 \mu \mathrm{g}$ one inhalation twice daily, or budesonide $200 \mu \mathrm{g}$ and formoterol $6 \mu \mathrm{g},\left(\right.$ Symbicort $\left.^{\mathrm{R}}\right)$, one inhalation twice daily for a period of 2 months. Subjects were defined as non-smokers if they had not smoked in the last year and had less than two pack-years of smoking, while smokers currently smoked more than ten cigarettes/day and had more than five pack-years of smoking (mean: $10.9 \pm 5.5$ pack years).

During the run-in period, peak expiratory flows (PEF) were measured twice daily as well as daily symptoms and bronchodilator use, and recorded on a diary card. During the study period, these parameters were measured 14 days before each study visit. Asthma control questionnaires were administered at entry in the study (visit 1), and then before and after each treatment.

During the run-in period, a thoracic examination, a baseline methacholine challenge, bronchodilator response assessment and allergy skin prick test were performed. On each visit, asthma control parameters, expiratory flows and airway inflammation as assessed by induced sputum analysis were measured.

All subjects provided an informed consent and the study was approved by the institutional Ethic Committees (Institut universitaire de cardiologie et de pneumologie de Québec and Sacré-Coeur Hospital).

\section{Subjects}

\section{Inclusion Criteria for All Groups}

1. Age ranging $18-45$ in order to minimise the possibility of including patients with smokinginduced Chronic Obstructive Pulmonary Disease (COPD).

2. Good health apart from asthma as determined by history and physical examination.

3. Smoking habits $\leq 20$ pack/years.

4. History consistent with asthma in accordance with the criteria proposed by the American Thoracic Society [16], showing an improvement in forced expiratory volume in one second $\left(\mathrm{FEV}_{1}\right) \geq 12 \%$ from baseline ten minutes after receiving $400 \mu \mathrm{g}$ of salbutamol.

5. $\mathrm{FEV}_{1}>70 \%$ predicted value.

6. Asthma sub-optimally controlled according to the Canadian asthma consensus guidelines, while using only a short-acting $\beta_{2}$-agonist on demand, but this condition had to be stable for at least 3 months before entering the trial. Patients should have required however no more than 3 doses of rescue medication per day (no more than 6 inhalations of salbutamol or 3 of terbutaline) [15]. Nasal steroids not allowed except if they were kept at the same dose throughout the study.

\section{Exclusion Criteria}

1. Subjects who were, in the opinion of the investigator, mentally or legally incapacitated thus preventing informed consent from being obtained.

2. Another pulmonary disorder than asthma or a coexisting illness that may affect the tests required.

3. Pregnant or lactating women.

4. Subjects unable to perform the tests or with contraindications to the tests proposed.

5. History of upper respiratory tract infection in the last month.

6. Use of oral or inhaled corticosteroid in the last 6 months.

\section{Measurements}

Questionnaire and Asthma Control Assessment: A validated questionnaire, the Asthma Control Scoring System (ACSS) [17], and the Juniper et al. Asthma Control Questionnaire (ACQ) [18] were used to assess asthma control for the last week before each visit. A standardized quality of life questionnaire (AQLQ) was filled by the patient at each visit [19].

Allergy Skin Tests: Skin prick tests were done with a battery of common airborne allergens. Atopy was defined as the presence of at least one positive ( $3 \mathrm{~mm}$ wheal or greater) response to allergens after ten minutes.

Spirometry: Expiratory flows were measured from flowvolume curves performed according to the American Thoracic Society (ATS) specifications [20]. Predicted values were from Knudson [21]. The $\mathrm{FEV}_{1}$ was calculated as the best of the three reproducible values. $\beta_{2}$-agonist response was determined by administering four inhalations of salbutamol $100 \mu \mathrm{g}$ and then measuring spirometry 10 minutes later.

Methacholine Challenge: Methacholine responsiveness was measured using the tidal volume method [22]. Briefly, concentrations of methacholine up to $32 \mathrm{mg} / \mathrm{ml}$ were used. Response was expressed as the provocative concentration of methacholine inducing a $20 \%$ fall in $\mathrm{FEV}_{1} \quad\left(\mathrm{PC}_{20}\right)$ methacholine.

Induced Sputum Analysis: Sputum was obtained with hypertonic saline according to the method described by Pin et al. and modified by Pizzichini et al., which involves inhaling increasing concentrations of saline $(3,4$, and $5 \%$ ) for seven minutes each through a mouthpiece without a valve or nose clip [23]. Two cytospins were prepared, dried and stained by DIFF Quik solutions (Dade Diagnostics, Aguada, USA) and a 400 non-squamous cell differential count was performed, including eosinophils, neutrophils, macrophages, lymphocytes and bronchial cells. The remaining cell suspension was spun at $500 \mathrm{~g}$ for $10 \mathrm{~min}$ and the supernatant was aspirated and stored at minus $80^{\circ} \mathrm{C}$ for Eosinophil Cationic Protein (ECP) and Myeloperoxydase (MPO) analysis. 
Rescue Medication Use and Exacerbations: We evaluated $\beta_{2}$-agonist need, number of awakenings due to asthma, and number of asthma episodes, defined as intercurrent asthma symptoms, during the last week of run-in and 2 weeks before each end of treatment.

Randomisation: Patients were double blind randomised from an external randomisation code.

Sample Size: We aimed to enrol 60 patients, 30 smokers and 30 non-smokers. We considered that the cross-over design would increase significantly the statistical power of such study and we believed that the cross-over period would be sufficient to avoid sufficient overlap of the previous treatment. We hypothesized that the improvement in asthma control as shown by the ACQ would be significantly greater in the smokers after treatment with budesonide/formoterol than after budesonide compared to non smokers. A difference of 0.5 in the ACQ score was considered as clinically significant. We considered that a group sample size of about 20 subjects in each group (33\% drop out) would allow to achieve $80 \%$ power to detect a difference of 0.6 in the ACQ between the smokers and the non smokers with estimated respective group standard deviations of 0.5 and 1.0 and with a significance level (alpha) of 0.05 using a two-sided Mann-Whitney test since the data were likely to be non normally distributed.

\section{Analysis}

The primary parameter was ACQ. Secondary parameters

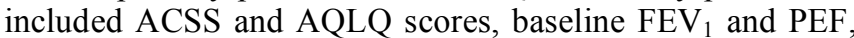
$\beta 2$ use, episodes of awakenings, number of asthma episodes and total and differential cell counts, ECP and MPO in induced sputum.

Table 1. Subjects' Characteristics

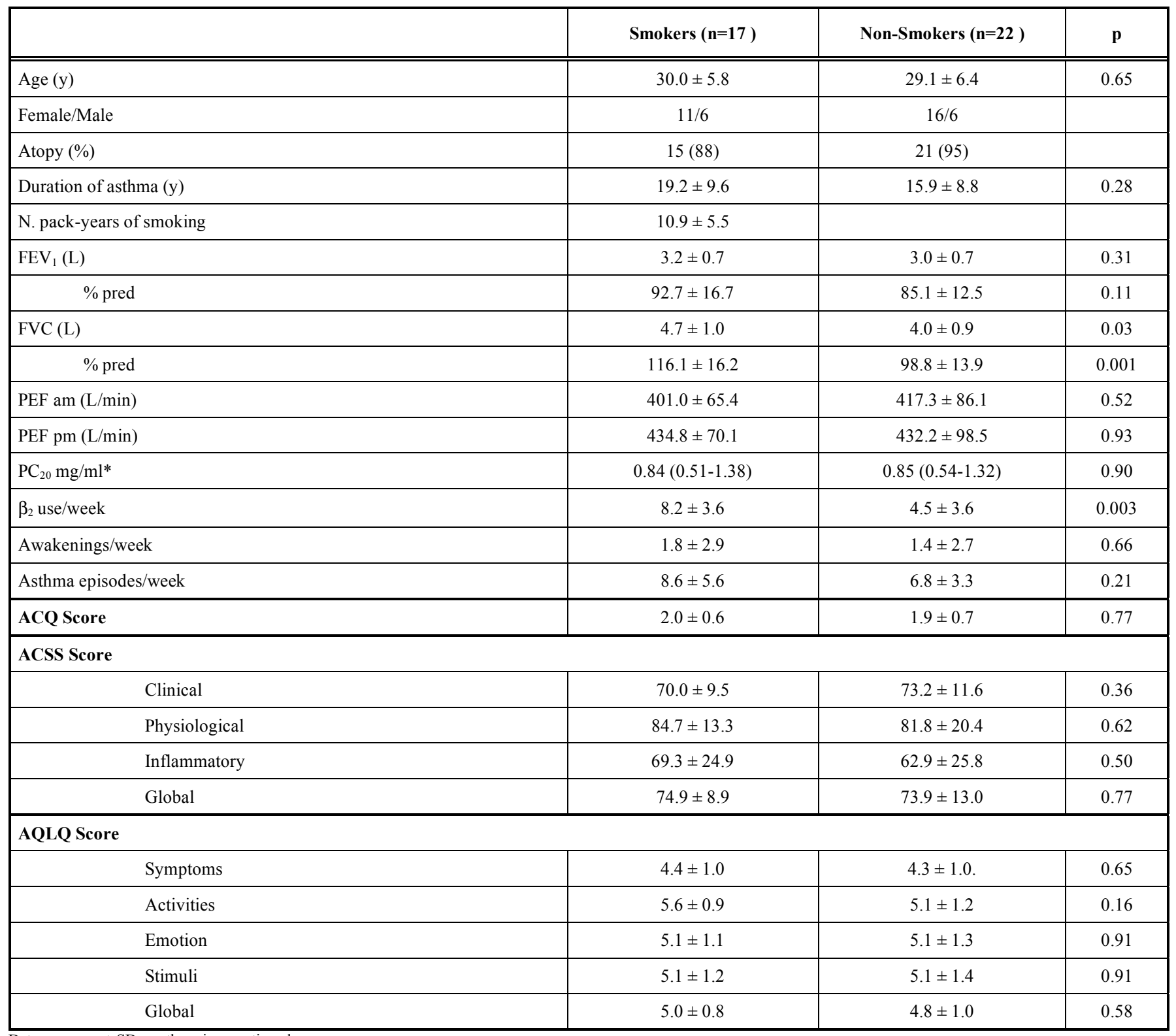


From subjects' characteristics data, one-way ANOVA and Fisher's exact test were used to analyze continuous and categorical variables respectively. All cell counts variables as well as $\mathrm{PC}_{20}$ were log-transformed to stabilize variance. Variables expressed in percentage were analysed using the $\sin ^{-1}(\sqrt{ })$ transformation. Statistical results from these parameters were expressed with transformed values. All data were analyzed using a cross-over design where each subject received two treatments (budesonide and budesonide/ formoterol) in one of the two sequences: budesonide, budesonide/formoterol, and budesonide/formoterol, budesonide. In each sequence, the scatter plot of the change in each patient's response over the two treatment periods showed high between-patient variability, suggesting defining the subjects as a random effect in the statistical model. Values before treatments were used as covariates as well as the comparisons between smoker and non-smoker subjects. The Kenward and Roger degree of freedom approximation was used as unbalanced settings occurred and this method has the advantage to produce the exact result. The normality assumption was verified with the Shapiro-Wilk test and the Brown and Forsythe's variation of Levene's test statistic was used to verify the homogeneity of variances. All assumptions were fulfilled. The results were considered significant with $\mathrm{p}$-values $<0.05$. The data were analyzed using the statistical package program SAS v9.1.3 (SAS Institute Inc., Cary, NC).

\section{RESULTS}

We screened 51 smoking and 69 non-smoking consecutive asthmatic subjects from Institut universitaire de cardiologie et de pneumologie de Québec, Quebec City and Sacré-Coeur Hospital, Montreal (Canada) asthma clinics. Of them, 29 smokers (S) and 31 non-smokers (NS) fulfilled the inclusion criteria and were randomized. From this group, 17 smokers and 22 non-smokers completed the study. Patients were withdrawn due to lost to follow-up (7S, 4NS), withdrawal of consent ( $2 \mathrm{~S}, 1 \mathrm{NS})$, adverse events ( $2 \mathrm{~S}, 3 \mathrm{NS})$ and non compliance (1S, 1NS).

\section{Baseline Subjects' Characteristics}

Baseline subjects' characteristics are summarized in Table 1. The two groups were similar with regard to age, severity and duration of asthma. There were more women than men and most patients had long-standing asthma. Smokers had a mean $( \pm$ SD) number of pack-years of cigarettes of $10.9 \pm 5.5$. Fifteen smokers $(88 \%)$ and 21 nonsmokers (95\%) were atopic.

Baseline ACQ, ACSS and AQLQ scores were not different between the two groups. On baseline, $\mathrm{FEV}_{1}$ and $\mathrm{PC}_{20}$ were similar between groups $(\mathrm{p}>0.05)$ but forced vital capacity $(\mathrm{FVC})$ was higher in smokers $(\mathrm{p}=0.03)$. Number of asthma episodes per week were similar in both groups but smokers reported more frequent bronchodilator use $(\mathrm{p}=0.003)$. The numbers and $\%$ of cells found in induced sputum, were similar in both groups $(p>0.05)$. Data are reported in Table 2 .

\section{Changes in Parameters Following Treatments}

\section{Asthma Control}

The ACQ scores assessed in the last week before each end of treatment were similar in smokers and non-smokers $(p=0.23)$. In both groups there was no treatment effect on the changes observed (Table $\mathbf{3}$ ).

From the ACSS questionnaire, expressed as a percentage of optimal values for the last week of treatments, smokers had a lower global asthma control score than non-smokers $(\mathrm{p}=0.03)$ (poorer control, particularly of the inflammatory component).

In regard to the ACSS questionnaire clinical and physiological scores, results were similar in smokers compared with non-smokers (respective $p$ values: 0.74, 0.62). Regarding ACSS score on airway inflammation, smokers had a lower score, with a higher $\%$ of eosinophils in sputum $(\mathrm{p}=0.002)$. Treatment effect was similar in smokers and non-smokers $(\mathrm{p}=0.87)$. In both groups, subjects

Table 2. Baseline Cells Analysis of Sputum

\begin{tabular}{|c|c|c|c|}
\hline & Smokers $(n=14)$ & Non-smokers $(n=13)$ & $\mathbf{p}$ \\
\hline Total cells (x 106/g) & $3.8(2.3-11.4)$ & $3.5(0.7-14.4)$ & 0.75 \\
\hline Neutrophils (x $10^{6} / \mathrm{g}$ ) \% & $\begin{array}{c}1.4(0.3-10.6) \\
49(11-93)\end{array}$ & $\begin{array}{c}0.6(0-4.2) \\
27.3(0-82.3)\end{array}$ & $\begin{array}{l}0.12 \\
0.17\end{array}$ \\
\hline Macrophages (x 10\% $/ \mathrm{g}) \%$ & $\begin{array}{c}1.9(0.7-3.5) \\
43.3(6.5-69.5)\end{array}$ & $\begin{array}{c}1.3(0-10.4) \\
58.5(9.8-97.0)\end{array}$ & $\begin{array}{l}0.80 \\
0.23\end{array}$ \\
\hline Lymphocytes (x 10\% /g) \% & $\begin{array}{c}0(0-0.1) \\
1.0(0.2-3.5)\end{array}$ & $\begin{array}{c}0(0-0.5) \\
1.1(0-5.5)\end{array}$ & $\begin{array}{l}0.39 \\
0.37\end{array}$ \\
\hline Bronchial epithelial cells (x 10 $10^{6}$ ) $\%$ & $\begin{array}{l}0.1(0-0.1) \\
1.8(0-4.0)\end{array}$ & $\begin{array}{c}0(0-0.3) \\
0.8(0-3.0)\end{array}$ & $\begin{array}{l}0.54 \\
0.28\end{array}$ \\
\hline $\mathrm{ECP}(\mathrm{ng} / \mathrm{ml})$ & $\begin{array}{c}56.0 \\
(5.3-423.2)\end{array}$ & $\begin{array}{c}285.7(23.5-1227.8) \\
(n=7)\end{array}$ & 0.20 \\
\hline MPO (ng/ml) & $\begin{array}{c}197.7 \\
(14.2-2004.1)\end{array}$ & $\begin{array}{c}176.5(20.2-2034.8) \\
(\mathrm{n}=9)\end{array}$ & 0.83 \\
\hline
\end{tabular}


Table 3. Treatment Responses to Pulmonary Function and Asthma Control

\begin{tabular}{|c|c|c|c|c|c|c|}
\hline & \multicolumn{2}{|c|}{ Smokers } & \multirow[b]{2}{*}{$\mathbf{p}$} & \multicolumn{2}{|c|}{ Non-Smokers } & \multirow[b]{2}{*}{$\mathbf{p}$} \\
\hline & $\begin{array}{c}\text { Budesonide } \\
\quad(n=17)\end{array}$ & $\begin{array}{c}\text { Budesonide }+ \\
\text { Formoterol }(n=17)\end{array}$ & & $\begin{array}{l}\text { Budesonide } \\
\quad(\mathrm{n}=\mathbf{2 2})\end{array}$ & $\begin{array}{c}\text { Budesonide }+ \\
\text { Formoterol }(n=22)\end{array}$ & \\
\hline $\mathrm{FEV}_{1} \%$ pred & $96.1 \pm 17.6$ & $97.1 \pm 17.7$ & 0.91 & $93.2 \pm 14.4$ & $93.6 \pm 12.5$ & 0.85 \\
\hline FVC $\%$ pred. & $116.7 \pm 16.3$ & $116.3 \pm 15.5$ & 0.74 & $103.0 \pm 19.4$ & $102.5 \pm 15.6$ & 0.98 \\
\hline $\mathrm{PEFam}^{\dagger}$ & $414 \pm 72$ & $430 \pm 63$ & 0.11 & $460 \pm 101$ & $467 \pm 95$ & 0.34 \\
\hline $\mathrm{PEFpm}^{\dagger}$ & $429 \pm 73$ & $445 \pm 61$ & 0.11 & $464 \pm 101$ & $476 \pm 96$ & 0.08 \\
\hline$\beta_{2}$ agonist use $^{\dagger}$ & $6.9 \pm 9.2$ & $5.9 \pm 5.2$ & 0.12 & $2.7 \pm 4.0$ & $3.5 \pm 5.1$ & 0.63 \\
\hline Awakening $^{\dagger}$ & $1.9 \pm 4.2$ & $1.3 \pm 1.9$ & 0.27 & $0.8 \pm 1.3$ & $0.6 \pm 1.3$ & 0.50 \\
\hline Asthma episodes ${ }^{\dagger}$ & $5.3 \pm 5.6$ & $7.2 \pm 6.6$ & 0.016 & $4.2 \pm 4.8$ & $2.5 \pm 2.4$ & 0.009 \\
\hline ACQ Score $^{\dagger}$ & $1.1 \pm 0.7$ & $1.2 \pm 0.7$ & 0.78 & $0.8 \pm 0.6$ & $0.9 \pm 0.7$ & 0.89 \\
\hline \multicolumn{7}{|l|}{ ACSS Score $^{\dagger}$} \\
\hline Clinical & $84.7 \pm 14.2$ & $98.8 \pm 16.5$ & 0.66 & $87.0 \pm 11.0$ & $84.5 \pm 21.5$ & 0.69 \\
\hline Physiological & $89.7 \pm 14.2$ & $91.2 \pm 15.8$ & 0.30 & $87.3 \pm 14.5$ & $89.1 \pm 13.4$ & 0.86 \\
\hline Inflammatory & $66.2 \pm 21.2$ & $75.0 \pm 13.7$ & 0.13 & $80.0 \pm 21.4$ & $84.6 \pm 16.6$ & 0.26 \\
\hline Global & $80.2 \pm 8.9$ & $81.9 \pm 10.9$ & 0.31 & $85.1 \pm 10.5$ & $86.7 \pm 10.3$ & 0.28 \\
\hline \multicolumn{7}{|l|}{ AQLQ Score ${ }^{\dagger \dagger}$} \\
\hline Symptoms & $5.6 \pm 0.8$ & $5.4 \pm 0.8$ & 0.78 & $6.0 \pm 1.0$ & $5.9 \pm 1.0$ & 0.62 \\
\hline Activities & $6.2 \pm 0.6$ & $6.1 \pm 0.6$ & 0.56 & $6.3 \pm 0.6$ & $6.3 \pm 0.7$ & 0.90 \\
\hline Emotion & $6.5 \pm 0.5$ & $7.0 \pm 3.5$ & 0.65 & $6.3 \pm 0.7$ & $6.3 \pm 0.9$ & 0.58 \\
\hline Stimuli & $5.9 \pm 0.7$ & $5.8 \pm 0.8$ & 0.87 & $6.1 \pm 1.1$ & $6.3 \pm 0.7$ & 0.42 \\
\hline Global & $6.0 \pm 0.6$ & $6.0 \pm 1.0$ & 0.99 & $6.2 \pm 0.8$ & $6.2 \pm 0.7$ & 0.84 \\
\hline
\end{tabular}

Data are mean \pm SD.

${ }^{\dagger}$ Last 2 weeks of treatment.

${ }^{\dagger \dagger}$ Last week of treatment.

receiving budesonide/formoterol increased significantly their inflammatory score, reflecting a decrease in their eosinophils in sputum $(\mathrm{p}=0.045)$ (Table 3).

Regarding $\beta 2$-agonist need assessed in the last 2 weeks before each end of treatment, smokers had a higher mean frequency of $\beta 2$-agonist use compared with non-smokers $(\mathrm{p}=0.03)$ (Table 3).

Number of awakenings due to asthma assessed in the last two weeks before each end of treatment were similar in smokers and non-smokers $(\mathrm{p}=0.32)$.

Treatment effect was similar and non significant in smokers and non-smokers whatever the above parameters analysed.

Smokers showed a higher number of asthma episodes compared to non-smokers $(\mathrm{p}=0.04)$. Smokers treated with budesonide/formoterol having a significant increase in their number of asthma episodes $(\mathrm{p}=0.016)$ while non-smoking subjects showed a significant decrease in these episodes $(\mathrm{p}=0.009)$ (Table 3).

\section{Asthma Quality of Life Questionnaire}

The mean global score of AQLQ questionnaire and various domains as symptoms, activities, emotions or stimulus were similar in smokers and non-smokers (respective $\mathrm{p}$ value: $0.58,0.18,0.25,0.36,0.21$ ). Treatment effect was similar and non significant in smokers and nonsmokers $(\mathrm{p}>0.05)$ (Table 3).

\section{Pulmonary Function Tests}

Post-treatment changes in $\mathrm{FEV}_{1}$, FVC, morning peak flow expiratory (PEF am) and night-time peak flow expiratory $(\mathrm{PEF} \mathrm{pm})$ were similar in smokers compared to non-smokers (respective $\mathrm{p}=0.48,0.64,0.15,0.23$ ). Treatment effect was also similar in smokers and nonsmokers (respective $\mathrm{p}$ values 0.98, 0.80, 0.73, 0.88). However evening PEF were significantly higher in both groups using budesonide/formoterol $(p=0.02)$ while other variables were similar $(\mathrm{p}>0.05)$ (Table 3$)$.

\section{Airway Inflammation}

The numbers and percentages of cells and markers found in induced sputum are reported in Table 4. Median (range) absolute sputum eosinophil, and lymphocyte counts, ECP and MPO were similar in smokers compared to non-smokers (respective p: $0.41,0.51,0.34,0.32,0.59$. We found an increased number of macrophages in non-smokers $(\mathrm{p}=0.03)$ ). No significant changes were found in the 2 groups using one or the other treatment $(\mathrm{p}>0.05)$ except for neutrophils. We found an increased number of neutrophils in sputum of the 2 
Table 4. Treatment Responses of Cells and Markers in Sputum

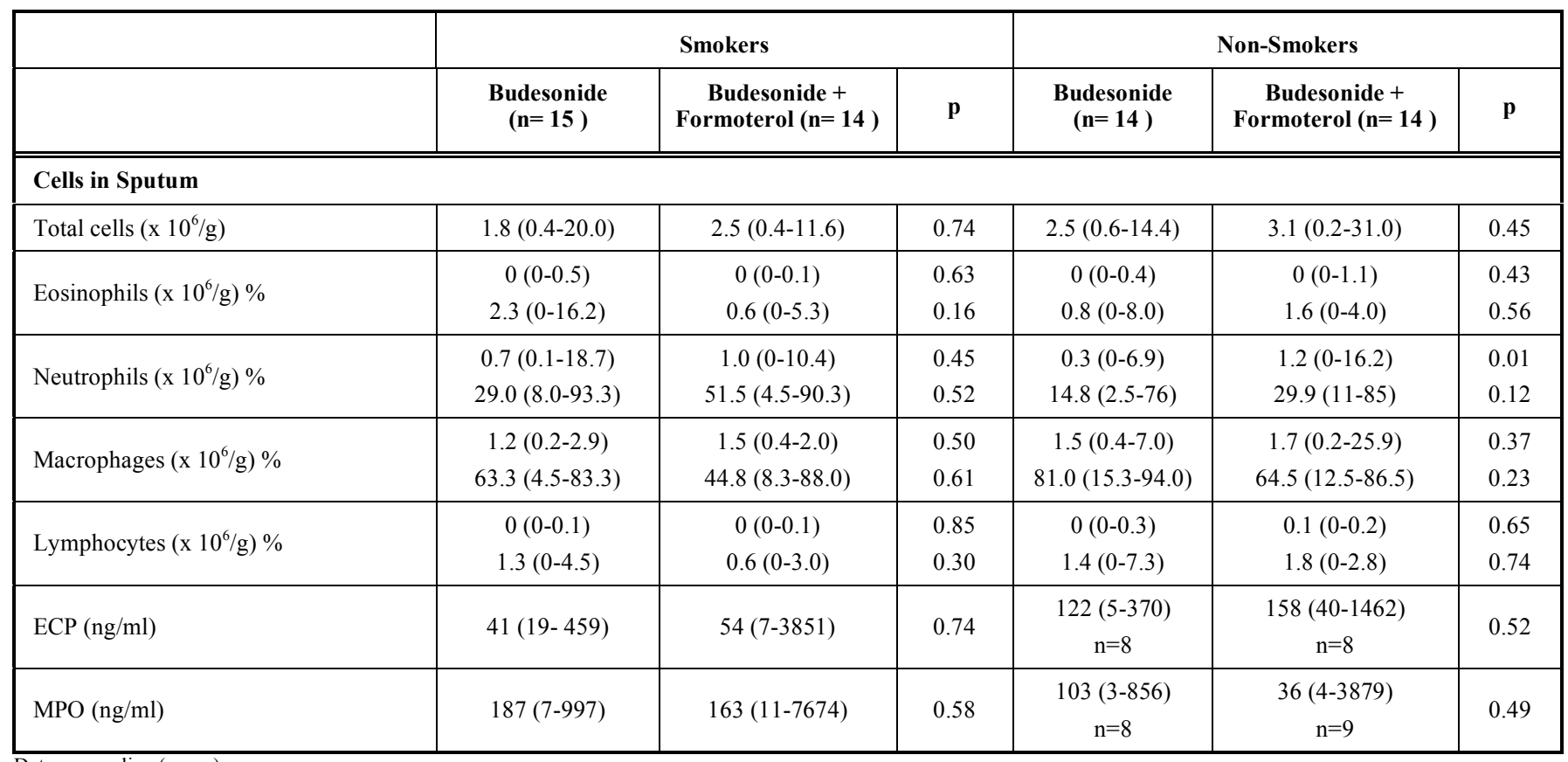

Data are median (range).

groups when on budesonide/formoterol $(p=0.04)$. Representative measurements are shown on Table 4.

\section{DISCUSSION}

It has been previously shown that adding a LABA to an ICS in asthmatic patients not optimally controlled with an ICS alone would improve significantly asthma control and reduce exacerbations, although there was no significant difference in most control parameters between ICS or ICS+LABA treatments in steroid-naïve mild asthma [24, 25]. It has also been shown that smoking could impair response to ICS treatments, and that it may be related to a different type of airway inflammation or other mechanisms leading to a reduced response to corticosteroids, such as those involving histone decarboxylase [9, 26-28]. It was therefore of interest to determine the effects of ICS compared to ICS combined to a LABA in smoking compared to non-smoking asthmatic patients, as there are no studies up to now, looking specifically at this question.

In this study, we found that a group of smokers with a mean of about 11 pack/years of smoking had similar changes in the various parameters tested when compared to nonsmokers apart from a reduction in asthma episodes on combination therapy in non-smokers compared to smokers. This study could not find a difference in response to both ICS and combination therapy with ICS or LABA, between smokers and non-smokers although this may be different with heavier or very long duration of smoking; we also cannot exclude that this is due to an insufficient sample size. We did not include in the study, patients with more than 20 pack/years of smoking to avoid enrolling patients with COPD. Our patients had mild asthma and moderate smoking as we wanted to avoid including smoking-induced COPD. It is possible nevertheless that difference between treatments could have been found in more severe patients or heavier smokers.
Although previous studies on response to ICS in smokers were done in a relatively similar number of patients as in our study, and as we had a crossover study design, increasing the power of statistical analysis, it is possible that significant differences could have been found with a larger sample size [12]. Even if we cannot exclude a type II error, we can nevertheless considered this trial as a valid pilot project to obtain data that would help support further investigation on the differential response between smoking and non-smoking asthmatic patients. Our results suggest that there are no differences in the pattern of response of these two groups in regard to the treatments offered although it could be of interest to test a larger number of patients.

We previously reported that asthmatic smokers had more frequent respiratory symptoms and evidence suggesting early COPD-like changes such as High-Resolution Chest Tomography (HRCT) emphysema-like abnormalities, more marked airflow limitation, and lower lung diffusion capacity than non-smoking asthmatic patients [10]. Furthermore, increased numbers of neutrophils have been found in smokers in induced sputum $[10,12]$. These two observations would suggest that smoking asthmatics would be less responsive to ICS although they may benefit more with a combination treatment with an ICS plus LABA. We could not confirm this possibility in our study, although in regard to respiratory symptoms, smokers were using their rescue bronchodilator more frequently than non-smokers. The similar response to ICS may be due to the lack of marked changes in the pattern of airway inflammation in these patients, with such degree of smoking. Indeed, in regard to airway inflammation, smokers had evidences of increased airway inflammation form ACSS scores, and seemed to have a lesser response to treatments in regard to the reduction in sputum eosinophils although this was not statistically significant. The increases in sputum neutrophils that were observed in both groups on combination therapy were not 
significant and difficult to explain. In smokers, it could have suggested an increased penetration of smoke into the airways, but this was also observed in non-smokers.

Further research is therefore needed to determine the comparative response to ICS, combination therapy between ICS and LABA and other agents according to the intensity of and duration smoking in asthmatic patients.

In conclusion, we found no significant difference between smoking and non-smoking asthmatic patients in regard to response to treatment with a budesonide or a combination of budesonide plus formoterol. This study brings useful information that suggests that potential changes in medication responses should be further explored in large number of patients who are heavier smokers.

\section{ACKNOWLEDGEMENTS}

Supported by AstraZeneca Canada Inc. Catherine Lemiere holds a scolarship from the Fonds de la recherche en santé du Québec (FRSQ).

\section{REFERENCES}

[1] Jha P, Ranson MK, Nguyen SN, Yach D. Estimates of global and regional smoking prevalence in 1995, by age and sex. Am J Public Health 2002; 92: 1002-6.

[2] Respiratory disease in Canada. Canadian Institute for Health Information, Canadian Lung Association, Health Canada, Statistics, Ottawa, Canada, September 2001. Available from: http://secure.cih i.ca/cihiweb/dispPage.jsp?cw page=AR $13 \mathrm{E}$

[3] Thomson NC, Chaudhuri R, Livingston E. Active cigarette smoking and asthma. Clin Exp Allergy 2003; 33: 1471-5.

[4] Lemiere C, Boulet LP. Cigarette smoking and asthma: a dangerous mix. Can Respir J 2005; 12: 79-80.

[5] Althuis M, Sexton M, Prybylski D. Cigarette smoking and asthma severity among adult asthmatics. J Asthma 1999; 36: 257-64.

[6] Ulrik CS, Lange P. Cigarette smoking and asthma. Monaldi Arch Chest Dis 2001; 56: 349-53.

[7] Lange P, Parner J, Vestbo J, Schnohr P, Jensen G. A 15 year follow-up study of ventilatory function in adults with asthma. $\mathrm{N}$ Engl J Med 1998; 339: 1194-200.

[8] Siroux V, Pin I, Oryszczyn M, Le Moual N, Kauffman F. Relationships of active smoking to asthma and asthma severity in the EGEA study. Epidemiological study on the Genetics and Environment of Asthma. Eur Respir J 2000; 15: 470-7.

[9] Thomson NC. Smokers with asthma: what are the management options? Am J Respir Crit Care Med 2007; 175: 749-50.

[10] Boulet LP, Lemiere C, Archambault F, Carrier G, Descary MC, Deschesnes F. Smoking and asthma: clinical and radiologic features, lung function, and airway inflammation. Chest 2006; 129 : 661-8.
[11] Pedersen B, Dahl R, Karlstrom R, Peterson CG, Venge P. Eosinophil and neutrophil activity in asthma in a one-year trial with inhaled budesonide: the impact of smoking. Am J Respir Crit Care Med 1996; 153: 1519-29.

[12] Chalmers GW, Macleod KJ, Little SA, Thomson LJ, McSharry CP Thomson NC. Influence of cigarette smoking on inhaled corticosteroid treatment in mild asthma. Thorax 2002; 57: 226-30.

[13] Chalmers GW, MacLeod KJ, Thomson L, Little SA, McSharry C, Thomson NC. Smoking and airway inflammation in patients with mild asthma. Chest 2001; 120: 1917-22.

[14] Global Initiatives on Asthma (GINA guidelines) www.ginasthma. com

[15] Lemière $\mathrm{C}$, Bai $\mathrm{T}$, Balter $\mathrm{M}$, et al. Adult Asthma Consensus Guidelines Update 2003. Can Respir J 2004; 11: 9A-18A.

[16] American Thoracic Society: Standards for the diagnosis of patients with COPD and asthma. Am Rev Respir Dis 1987; 136: 225-44.

[17] Leblanc A, Robichaud P, Lacasse Y, Boulet LP. Quantification of asthma control : validation of the Asthma Control Scoring System. Allergy 2007; 62: 120-5.

[18] Juniper EF, O'Byrne PM, Guyatt GH, Ferrie PJ, King DR Development and validation of a questionnaire to measure asthma control. Eur Respir J 1999; 14: 902-7.

[19] Juniper EF, Guyatt GH, Cox FM, Ferrie PJ, King DR Development and validation of the mini asthma quality of life questionnaire. Eur Respir J 1999; 14: 32-8.

[20] ATS statement. Standardization of spirometry-1987 update. Am Rev Respir Dis 1987; 136: 1285-98.

[21] Knudson RJ, Lebowitz MD, Holberg CJ, Burrows B. Changes in the normal maximal expiratory flow-volume curve with growth and aging. Am Rev Respir Dis 1983; 127: 725-34.

[22] Juniper EF, Cockcroft DW, Hargreave FE. Eds. Astra Draco AB Histamine and Methacholine inhalation Tests: A laboratory Tida Breathing Protocol. Lund, Sweden 1991.

[23] Pizzichini E, Hargreave FE, Pizzichini E, et al. Assessment of airway inflammation. In: Barnes $\mathrm{P}$, Grunstein $\mathrm{M}$, Leff A, Woolcock A, Eds. Asthma. Philadelphia PA: Lippincott-Raven 1997; vol. 2: pp. 1433-50.

[24] Woolcock A, Lundback B, Ringdal N, Jacques LA. Comparison of addition of salmeterol to inhaled steroids with doubling of the dose of inhaled steroids. Am J Respir Crit Care Med 1996; 153: 1481-8.

[25] O'Byrne PM, Barnes PJ, Rodriguez-Roisin R, et al. A low dose inhaled budesonide and formoterol in mild persistent asthma: the OPTIMA randomized trial. Am J Respir Crit Care Med 2001; 164 . 1392-7.

[26] Thomson NC, Shepherd M, Spears M, Chaudhuri R. Corticosteroid insensitivity in smokers with asthma: clinical evidence, mechanisms, and management. Treat Respir Med 2006; 5: 467-81.

[27] Thomson NC, Chaudhuri R, Livingston E. Asthma and cigarette smoking. Eur Respir J 2004; 24: 822-33.

[28] Lazarus SC, Chinchilli VM, Rollings NJ, et al. National heart lung and blood institute's asthma clinical research network. Smoking affects response to inhaled corticosteroids or leukotriene receptor antagonists in asthma. Am J Respir Crit Care Med 2007; 175: 78390. 